\title{
Clinico-epidemiological characteristics of men and women with a new diagnosis of chronic obstructive pulmonary disease: a database (SIDIAP) study
}

Josep Montserrat-Capdevila 1,2,3,4*(D), Josep Ramon Marsal ${ }^{5}$, Marta Ortega ${ }^{2,4,6}$, Maria Teresa Castañ-Abad ${ }^{2,4}$, Miquel Alsedà $3,4,7$, Ferran Barbé $e^{3,4,8,9}$ and Pere Godoy $3,4,7,10$

\begin{abstract}
Background: The risk of developing Chronic Obstructive Pulmonary Disease (COPD), the associated comorbidities and response to bronchodilators might differ in men and women. The objective of this study was to determine the prevalence of COPD and the clinic-epidemiological characteristics of primary care patients with COPD according to gender.

Methods: This is a cross-sectional study using electronic healthcare records Catalonia (Spain), during the 01/01/2012-31/12/2017 period. Patients from the SIDIAP database (System for the Development of Research in Primary Care) were included (5,800,000 patients registered in 279 primary care health centres). Clinic-demographic characteristics, comorbidities and blood tests results were collected for each patient. Adjusted OR (ORa) with logistic regression methods were used to determine variables associated with men and women.

Results: From an initial sample of 800,899 people, 24,135 (3\%) were considered COPD patients, and 22.9\%were women. The most common risk factors in women were bronchiectasis $(\mathrm{ORa}=20.5, \mathrm{SD}=19.5-21.6)$, age $>71$ years $(\mathrm{ORa}=18.8 ; \mathrm{SD}=17.3-20.5)$, cor pulmonale ( $\mathrm{ORa}=5.2 ; \mathrm{SD}=4.3-6.7)$ and lung cancer $(\mathrm{ORa}=3.6, \mathrm{SD}=3.2-4.0)$. Men and women presented the same comorbidities, though the strength of association was different for each gender.

Conclusions: Patients suffering high comorbidity rates. Comorbidities are similar in men and women, although the strength of association varies according to gender. Women are more susceptible to the harmful effects of smoking and present a higher proportion of bronchiectasis and OSAS.
\end{abstract}

Keywords: Chronic obstructive pulmonary disease, Prevalence, Epidemiology

\section{Background}

Chronic Obstructive Pulmonary Disease (COPD) is a condition which causes high morbidity and mortality globally [1], and is currently considered one of the

*Correspondence: jmontser@alumni.unav.es

1 Unitat Docent Multiprofessional d'Atenció Familiar i Comunitària

(UDMAFiC) Lleida-ICS, Gerència Territorial de Lleida ICS, Lleida, Catalonia,

Spain

Full list of author information is available at the end of the article main public health issues [2]. While WHO estimates that there are 251 million people affected with COPD globally [2], the EPISCAN study (Epidemiologic Study of COPD in Spain) reported that in Spain over a million and a half patients (73\%) remained undiagnosed and untreated, and thus at higher risk of exacerbations and disease progression [2]. The main prevalence studies of COPD in the Spanish population are IBERPOC and EPISCAN. In 1997, IBERPOC showed a COPD prevalence of $9.1 \%$, similar to the prevalence found a 
decade later by EPISCAN (10.2\%) [3]. COPD prevalence is highly heterogeneous, and it varies according to geographical location, the sample used and the definition of the disease. A systematic review on the prevalence of COPD in Europe found prevalence ranging between 2.1 and $26.1 \%$ in people over 40 years of age [4]. In the Vallès region of Catalonia, the prevalence of COPD using the criteria of the British Thoracic Society was $7.2 \%$ (10.4\% in men and $4.1 \%$ in women) [5]. A recent study conducted by our group in the population of Lleida (Catalonia) showed a prevalence of $14.5 \%$ ( $16.1 \%$ in men and $12.3 \%$ in women) [6].

COPD is associated with age, smoking [7] and cardiovascular diseases [8]. The risk associated with COPD might be similar to that of widely accepted cardiovascular factors such as hypertension and hypercholesterolaemia [8]. Various studies have pointed at the high prevalence of cardiovascular diseases, diabetes, kidney failure and other diseases associated with COPD [9].

Patients with COPD attend frequently primary care and emergency services for problems related to comorbidities and exacerbation [10]. Consequently, primary care patients can be considered a suitable sample of the general population. Some studies indicate that risk patterns might be different in men and women [11, 12], with different susceptibilities to develop COPD, associated comorbidities and response to bronchodilators [11]. Understanding gender differences in risk factors and comorbidities related to COPD might contribute to minimise their impact and improve the quality of life of these patients [13].

The objective of this study is to determine the prevalence of COPD and the clinico-epidemiological characteristics by gender in patients who attended primary care centres in Catalonia during the 2012-2017 period.

\section{Methods}

Observational epidemiological study on the prevalence of COPD according to primary care consultations in Catalonia (Spain), with data originating from electronical medical records from 01/01/2012 to 31/12/2017. The study aimed to discriminate clinico-epidemiological characteristics between genders. Participants were eligible patients included in the SIDIAP (System for the Development of Research in Primary Care) [14], a database with anonymised information from 5,800,000 patients assigned to 279 primary care centres of the Catalan Health Institute (approximately $80 \%$ of the Catalan population). In Catalonia, health professionals use ICD-10 to classify diseases in the electronic medical records (eCAP).

\section{Population with a new diagnosis of COPD}

Patients with COPD were identified for each year of the study period (2012-2017) using a diagnostic algorithm developed in previous studies that used similar databases [15]: Following GOLD [16] guidelines, patients over 40 years of age diagnosed with COPD, emphysema or chronic bronchitis and with FEV1/FVC $<0.7$ were included to perform spirometry. Patients diagnosed with COPD with spirometry result unknown, who were smokers/ex-smokers and received bronchodilator therapy (excluding treatment with cromoglycate and antileukotrienes), or who had never been smokers but received bronchodilator therapy (excluding treatment with cromoglycate and antileukotrienes) were also included. Patients not diagnosed with COPD but with spirometry results of FEV1/FVC $<0.7$, not diagnosed nor treated for asthma were also included (see Fig. 1.).

Information on clinico-demographic characteristics, including history of smoking and alcohol consumption, comorbidities, blood tests results, bronchodilator therapy and immunizations (influenza and pneumococcal) was obtained for each patient. Severity of COPD was evaluated in accordance to the most recent review of the 2018 GOLD Report [17].

The comorbidities (heart failure, ischemic heart disease, diabetes and prediabetes, chronic kidney disease, atrial fibrillation, anaemia, hypertension, dyslipidaemia, stroke and lung cancer) were obtained from the primary care electronic medical records and the hospital discharge minimum data set.

The study was approved by the Clinical Research Ethics Committee of the Institut d'Investigació en Atenció Primària Jordi Gol of Barcelona (P13/063).

\section{Statistical analysis}

All data originated from the SIDIAP database. Patients were classified in two main groups (with and without characteristics suggestive of COPD) (Fig. 1). Data on the characteristics of the patients, diagnoses recorded by family doctors, and pharmacological treatment dispensed in pharmacies (in Spain, medicines are subsidized by the universal health care system) were collected. Variables were described with mean and standard deviation in case of continuous variables, and with absolute and relative frequencies in case of categorical variables. Differences between groups were analysed using Student's $t$-test for continuous and Chi-squared test for categorical variables. Differences between groups were estimated calculating the difference of proportions and means. Logistic regression was used to estimate the crude and adjusted effects in both genders. The logistic regression models for men and 


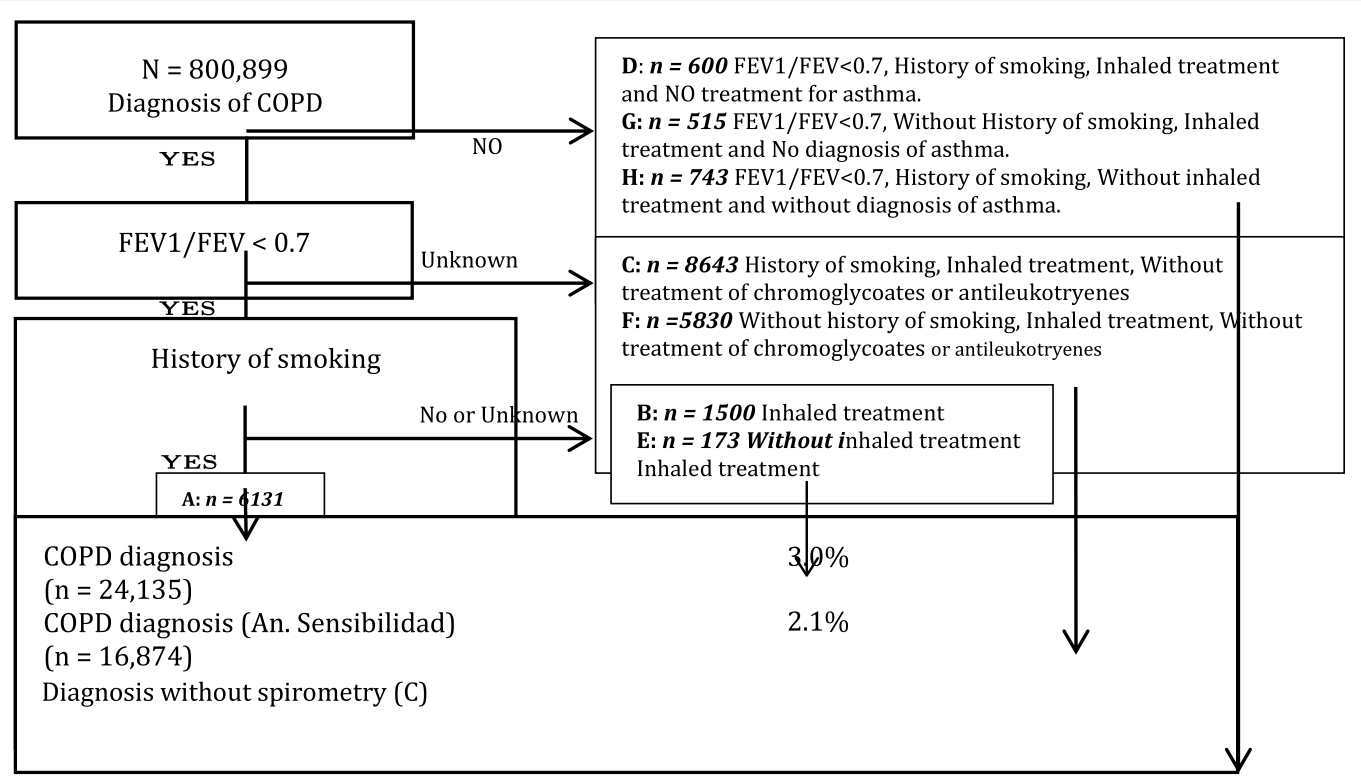

Fig. 1 Flowchart of the study patients

women were built using backward elimination, with a significance threshold of $p<0.1$.

\section{Results}

A total of 24,135 (3\%) out of the 800,899 people of the sample were considered to present clinical characteristics suggestive of COPD (Fig. 1); 22.9\% were women, with an average age of 72 years $(S D=11)$. The highest proportion of patients with COPD was in 71 to 80 year age group $(32.8 \%)$. The proportion of patients that were smokers or ex-smokers was $66.8 \%$ in patients diagnosed with COPD, compared to $31.5 \%$ in patients without COPD $(p<0.001)$. In relation to alcohol consumption, $39.8 \%$ of patients with COPD admitted to a low, moderate or high risk drinking, compared to $31.1 \%$ of patients with no COPD $(p<0.001)$. With respect to severity (GOLD), $49.1 \%$ patients with COPD were classified as moderate and $38.5 \%$ as severe. The average forced expiratory volume in one second (FEV1) in patients with COPD was $57.7(\mathrm{SD}=19.8)$. Table 1 shows the remaining variables.

Table 2 shows comorbidities and blood tests results (fibrinogen and C-reactive protein in peripheral blood) of patients with and without a COPD diagnosis. Up to $26.7 \%$ of patients with COPD had a diagnosis of type 2 diabetes, $6.6 \%$ of prediabetes (capillary glycaemia between 110 and $125 \mathrm{mg} / \mathrm{dL}$ ), 59.1\% presented hypertension (HT) and $45.7 \%$ dyslipidaemia. Additionally, $13.1 \%$ had anaemia, $11.8 \%$ atrial fibrillation, $8.8 \%$ ischaemic cardiomyopathy, $11.7 \%$ chronic kidney disease, 9.4\% heart failure, $8.1 \%$ had a history of stroke and $2.1 \%$ of lung cancer. Regarding blood tests results, mean fibrinogen in peripheral blood in patients with COPD was $407.2 \mathrm{mg} / \mathrm{dL}(\mathrm{SD}=105.7)$ and mean $\mathrm{C}$-reactive protein $(\mathrm{PCR}) 15.3(\mathrm{SD}=32.5)$. For all described comorbidities and blood tests results, statistically significant differences were found in COPD versus non COPD patients.

Age is strongly associated to COPD in both genders, but the effect is higher in men. Moderate and high alcohol consumption in men represents 1.3 risk of COPD $(p<0.001)$. A history of smoking (smoker or ex-smoker) multiplies this risk by $3.5(p<0.01)$. Men with bronchiectasis presented a risk 20.5 times higher of suffering from COPD $(p<0.001)$. Other frequent comorbidities in patients with COPD were anaemia $(\mathrm{aOR}=1.2 ; p<0.001)$ and ischaemic cardiomyopathy $(\mathrm{aOR}=1.2 ; p<0.001)$. Cor pulmonale and heart failure were also more prevalent amongst COPD patients $(\mathrm{aOR}=5.3 ; p<0.001$ and $\mathrm{aOR}=2.4 ; p<0.001$, respectively). Table 3 describes the crude and adjusted effect of comorbidities in men.

In women, the risk to develop COPD between 61 and 70 years of age increased by 4.7 , and by 14.5 from 80 years onwards $(p<0.001)$. While low alcohol consumption did not increase the risk to develop COPD, $(\mathrm{aOR}=0.9$; $p=0.22$ ), moderate to high drinking increased the risk by $1.6(p<0.001)$. Bronchiectasis increased by 27.1 the risk to develop COPD $(p<0.001)$. History of smoking increased almost five fold the risk to develop COPD $(\mathrm{aOR}=4.7 ; p<0.001)$. In women with COPD, comorbidities such as cor pulmonale and history of lung cancer were 3 times higher $(\mathrm{aOR}=3.1 ; p<0.001$ and $\mathrm{aOR}=3.6$; $p<0.001$, respectively). Table 4 shows the remaining comorbidities. 
Table 1 Characteristics of SIDIAP patients at the beginning of the study

\begin{tabular}{|c|c|c|c|c|c|c|c|c|}
\hline & \multicolumn{2}{|c|}{$\begin{array}{l}\text { No } \\
(n=776,764 ; 97 \%)\end{array}$} & \multicolumn{2}{|c|}{$\begin{array}{l}\text { Yes } \\
(n=24,135 ; 3 \%)\end{array}$} & \multirow[t]{2}{*}{ Dif } & \multicolumn{2}{|c|}{$\begin{array}{l}\text { Total } \\
(\mathrm{n}=800,899 ; 100 \%)\end{array}$} & \multirow[t]{2}{*}{$p$} \\
\hline & $\mathbf{N}$ & n (\%) & $\mathrm{N}$ & n (\%) & & $\mathrm{N}$ & n (\%) & \\
\hline Gender (female) & 776,764 & 406,346 (52.3\%) & 24,135 & $5523(22.9 \%)$ & $-29.4 \%$ & 800,899 & $411,869(51.4 \%)$ & $<0.001$ \\
\hline Age & 776,764 & $60 \pm 14$ & 24,135 & $72 \pm 11$ & 12 & 800,899 & $60 \pm 14$ & $<0.001$ \\
\hline Grouped Age & 782,055 & & 18,844 & & & 800,899 & & $<0.001$ \\
\hline $41-50$ & & $254,121(32.5 \%)$ & & $952(5.1 \%)$ & $-27.4 \%$ & & 255,073 (31.8\%) & \\
\hline $51-60$ & & $192,339(24.6 \%)$ & & $2964(15.7 \%)$ & $-8.9 \%$ & & $195,303(24.4 \%)$ & \\
\hline $61-70$ & & 153,292 (19.6\%) & & $5471(29 \%)$ & $9.4 \%$ & & $158,763(19.8 \%)$ & \\
\hline $71-80$ & & $107,013(13.7 \%)$ & & $6174(32.8 \%)$ & $19.1 \%$ & & $113,187(14.1 \%)$ & \\
\hline 80 or more & & 75,290 (9.6\%) & & $3283(17.4 \%)$ & $7.8 \%$ & & 78,573 (9.8\%) & \\
\hline Smoking History $(Y)$ & 776,764 & $244,600(31.5 \%)$ & 24,135 & $16,117(66.8 \%)$ & $35.3 \%$ & 800,899 & $260,717(32.6 \%)$ & $<0.001$ \\
\hline Alcohol Consumption & 371,525 & & 17,843 & & & 389,368 & & $<0.001$ \\
\hline No consumption & & 255,958 (68.9\%) & & 10,734 (60.2\%) & $-8.7 \%$ & & $266,692(68.5 \%)$ & \\
\hline Low Risk & & $107,170(28.8 \%)$ & & 6374 (35.7\%) & $6.9 \%$ & & $113,544(29.2 \%)$ & \\
\hline Moderate Risk & & 8301 (2.2\%) & & 725 (4.1\%) & $1.8 \%$ & & $9026(2.3 \%)$ & \\
\hline High Risk & & $96(0 \%)$ & & $10(0.1 \%)$ & $0.0 \%$ & & $106(0 \%)$ & \\
\hline Waist Circumference & 66,004 & $101.6 \pm 12.3$ & 4183 & $105.8 \pm 12.7$ & 4.14 & 70,187 & $101.9 \pm 12.4$ & $<0.001$ \\
\hline Missing & 776,764 & 710,760 (91.5\%) & 24,135 & $19,952(82.7 \%)$ & $-8.8 \%$ & 800,899 & 730,712 (91.2\%) & $<0.001$ \\
\hline Grouped BMI & 280,871 & & 15,400 & & & 296,271 & & 0.310 \\
\hline Normal & & $59,635(21.2 \%)$ & & $3306(21.5 \%)$ & $0.2 \%$ & & $62,941(21.2 \%)$ & \\
\hline Overweight & & $120,728(43 \%)$ & & $6451(41.9 \%)$ & $-1.1 \%$ & & $127,179(42.9 \%)$ & \\
\hline Obesity & & $100,508(35.8 \%)$ & & $5643(36.6 \%)$ & $0.9 \%$ & & $106,151(35.8 \%)$ & \\
\hline Gold grouped & & & 9746 & & & NA & & \\
\hline I & & & & $1205(12.4 \%)$ & & & & \\
\hline$\|$ & & & & 4788 (49.1\%) & & & & \\
\hline III-IV & & & & $3753(38.5 \%)$ & & & & \\
\hline \multicolumn{9}{|c|}{ Without bronchodilation } \\
\hline FEV1/FVC & & & 9213 & $59.6 \pm 11.4$ & & & & \\
\hline FEV1 & & & 9054 & $57.7 \pm 19.8$ & & & & \\
\hline FVC & & & 8826 & $100.1 \pm 201.6$ & FVC & & & 8826 \\
\hline
\end{tabular}

Table 2 Comorbidities and blood tests results in patients with and without COPD

\begin{tabular}{|c|c|c|c|c|c|c|c|c|}
\hline \multirow[t]{2}{*}{ COPD } & \multicolumn{2}{|c|}{$\begin{array}{l}\text { No } \\
(n=776,764 ; 97 \%)\end{array}$} & \multicolumn{2}{|c|}{$\begin{array}{l}\text { Yes } \\
(n=24,135 ; 3 \%)\end{array}$} & \multirow[t]{2}{*}{ Dif } & \multicolumn{2}{|c|}{$\begin{array}{l}\text { Total } \\
(n=800,899 ; 100 \%)\end{array}$} & \multirow[t]{2}{*}{$p$} \\
\hline & $\mathbf{N}$ & n (\%) & $\mathrm{N}$ & n (\%) & & $\mathbf{N}$ & n (\%) & \\
\hline $\mathrm{DM} 2(\mathrm{Y})$ & 776,764 & $98,932(12.7 \%)$ & 24,135 & $6453(26.7 \%)$ & $14.0 \%$ & 800,899 & $105,385(13.2 \%)$ & $<0.001$ \\
\hline Prediabetes $(Y)$ & 776,764 & $29,232(3.8 \%)$ & 24,135 & $1588(6.6 \%)$ & $2.8 \%$ & 800,899 & $30,820(3.8 \%)$ & $<0.001$ \\
\hline Anaemia $(Y)$ & 776,764 & $60,875(7.8 \%)$ & 24,135 & $3160(13.1 \%)$ & $5.3 \%$ & 800,899 & $64,035(8 \%)$ & $<0.001$ \\
\hline Ischaemic Cardiomyopathy (Y) & 776,764 & $18,812(2.4 \%)$ & 24,135 & $2134(8.8 \%)$ & $6.4 \%$ & 800,899 & $20,946(2.6 \%)$ & $<0.001$ \\
\hline Dyslipidaemia (Y) & 776,764 & $250,256(32.2 \%)$ & 24,135 & $11,039(45.7 \%)$ & $13.5 \%$ & 800,899 & $261,295(32.6 \%)$ & $<0.001$ \\
\hline$A F(Y)$ & 776,764 & $24,423(3.1 \%)$ & 24,135 & $2852(11.8 \%)$ & $8.7 \%$ & 800,899 & $27,275(3.4 \%)$ & $<0.001$ \\
\hline Hypertension $(Y)$ & 776,764 & $262,190(33.8 \%)$ & 24,135 & $14,256(59.1 \%)$ & $25.3 \%$ & 800,899 & $276,446(34.5 \%)$ & $<0.001$ \\
\hline Chronic kidney failure $(Y)$ & 776,764 & $29,259(3.8 \%)$ & 24,135 & $2823(11.7 \%)$ & $7.9 \%$ & 800,899 & $32,082(4 \%)$ & $<0.001$ \\
\hline Heart Failure $(Y)$ & 776,764 & $13,253(1.7 \%)$ & 24,135 & $2672(11.1 \%)$ & $9.4 \%$ & 800,899 & $15,925(2 \%)$ & $<0.001$ \\
\hline Stroke $(Y)$ & 776,764 & $22,330(2.9 \%)$ & 24,135 & $1944(8.1 \%)$ & $5.2 \%$ & 800,899 & $24,274(3 \%)$ & $<0.001$ \\
\hline Lung Cancer (Y) & 776,764 & $1740(0.2 \%)$ & 24,135 & $552(2.3 \%)$ & $2.1 \%$ & 800,899 & $2292(0.3 \%)$ & $<0.001$ \\
\hline Fibrinogen & 59,544 & $375.2 \pm 94.3$ & 3556 & $407.2 \pm 105.7$ & 32.01 & 63,100 & $377 \pm 95.3$ & $<0.001$ \\
\hline C-reactive protein & 56,406 & $8.3 \pm 20.9$ & 3367 & $15.3 \pm 32.5$ & 7.05 & 59,773 & $8.7 \pm 21.7$ & $<0.001$ \\
\hline
\end{tabular}


Table 3 Univariate and multivariate analysis of the study variables in men

\begin{tabular}{|c|c|c|c|c|c|c|c|c|}
\hline \multirow[t]{2}{*}{ Men } & \multicolumn{2}{|c|}{ Descriptive } & \multicolumn{3}{|c|}{ Crude effect } & \multicolumn{3}{|c|}{ Adjusted effect } \\
\hline & $\mathbf{N}$ & n (\%) & OR & $\mathrm{Cl}(95 \%)$ & $p$ & OR & $\mathrm{Cl}(95 \%)$ & $p$ \\
\hline Age grouped & 389,030 & & & & & & & \\
\hline $41-50$ & & $134,104(34.5 \%)$ & 1 & - & & 1 & - & \\
\hline $51-60$ & & $97,416(25 \%)$ & 4.4 & $(4.1-4.8)$ & $<0.001$ & 3.4 & $(3.1-3.7)$ & $<0.001$ \\
\hline $61-70$ & & 76,965 (19.8\%) & 13.2 & $(12.2-14.3)$ & $<0.001$ & 8.7 & $(8-9.4)$ & $<0.001$ \\
\hline $71-80$ & & $51,763(13.3 \%)$ & 27.1 & $(25.1-29.3)$ & $<0.001$ & 18.8 & $(17.3-20.5)$ & $<0.001$ \\
\hline 80 or more & & 28,782 (7.4\%) & 34.2 & $(31.5-37.1)$ & $<0.001$ & 29.1 & $(26.6-31.8)$ & $<0.001$ \\
\hline Smoking & 389,030 & $173,001(44.5 \%)$ & 4.1 & $(4-4.3)$ & $<0.001$ & 3.5 & $(3.4-3.6)$ & $<0.001$ \\
\hline Bronchiectasis & 389,030 & $10,479(2.7 \%)$ & 31.3 & $(30-32.7)$ & $<0.001$ & 20.5 & $(19.5-21.6)$ & $<0.001$ \\
\hline Cor Pulmonale & 389,030 & $451(0.1 \%)$ & 21.0 & $(17.4-25.2)$ & $<0.001$ & 5.3 & $(4.3-6.7)$ & $<0.001$ \\
\hline Lung Cancer & 389,030 & $1790(0.5 \%)$ & 8.2 & $(7.4-9.1)$ & $<0.001$ & 3.6 & $(3.2-4)$ & $<0.001$ \\
\hline Heart Failure & 389,030 & 7155 (1.8\%) & 7.9 & $(7.4-8.3)$ & $<0.001$ & 2.4 & $(2.3-2.6)$ & $<0.001$ \\
\hline OSAS & 389,030 & 8767 (2.3\%) & 2.9 & $(2.7-3.1)$ & $<0.001$ & 1.7 & $(1.6-1.9)$ & $<0.001$ \\
\hline Osteopathy & 389,030 & $3228(0.8 \%)$ & 4.4 & $(4.1-4.9)$ & $<0.001$ & 1.6 & $(1.5-1.8)$ & $<0.001$ \\
\hline Alcohol Consumption Risk Rate & 389,030 & & & & & & & \\
\hline No intake & & $94,120(24.2 \%)$ & 1 & & $<0.001$ & 1 & & $<0.001$ \\
\hline Low & & $80,222(20.6 \%)$ & 0.9 & $(0.9-0.9)$ & $<0.001$ & 0.9 & $(0.9-1)$ & $<0.001$ \\
\hline Moderate or High & & $7855(2 \%)$ & 1.1 & $(1-1.2)$ & 0.006 & 1.3 & $(1.1-1.4)$ & $<0.001$ \\
\hline NA & & $206,833(53.2 \%)$ & 0.3 & $(0.3-0.3)$ & $<0.001$ & 0.7 & $(0.7-0.8)$ & $<0.001$ \\
\hline Depression & 389,030 & $30,568(7.9 \%)$ & 1.4 & $(1.4-1.5)$ & $<0.001$ & 1.3 & $(1.2-1.3)$ & $<0.001$ \\
\hline Ischaemic Cardiomyopathy & 389,030 & $14,546(3.7 \%)$ & 3.1 & $(2.9-3.3)$ & $<0.001$ & 1.2 & $(1.1-1.3)$ & $<0.001$ \\
\hline AF & 389,030 & $13,974(3.6 \%)$ & 4.1 & $(3.9-4.3)$ & $<0.001$ & 1.2 & $(1.1-1.3)$ & $<0.001$ \\
\hline Anaemia & 389,030 & $17,209(4.4 \%)$ & 3.3 & $(3.2-3.5)$ & $<0.001$ & 1.2 & $(1.1-1.2)$ & $<0.001$ \\
\hline Chronic kidney failure & 389,030 & 16,268 (4.2\%) & 3.5 & $(3.3-3.6)$ & $<0.001$ & 1.1 & $(1-1.2)$ & 0.001 \\
\hline Dyslipidaemia & 389,030 & 122,087 (31.4\%) & 1.9 & $(1.8-1.9)$ & $<0.001$ & 1.0 & $(0.9-1)$ & 0.009 \\
\hline Hypertension & 389,030 & $131,174(33.7 \%)$ & 2.9 & $(2.8-3)$ & $<0.001$ & 0.9 & $(0.9-1)$ & 0.004 \\
\hline DM2 & 389,030 & $58,219(15 \%)$ & 2.3 & $(2.3-2.4)$ & $<0.001$ & 0.9 & $(0.9-1)$ & $<0.001$ \\
\hline Grouped BMI & 389,030 & & & & & & & \\
\hline Normal & & 25,352 (6.5\%) & 1 & - & & 1 & - & $<0.001$ \\
\hline Overweight & & $67,457(17.3 \%)$ & 0.8 & $(0.7-0.8)$ & $<0.001$ & 0.8 & $(0.7-0.8)$ & $<0.001$ \\
\hline Obesity & & $47,140(12.1 \%)$ & 0.9 & $(0.8-0.9)$ & $<0.001$ & 0.9 & $(0.8-0.9)$ & $<0.001$ \\
\hline NA & & $249,081(64 \%)$ & 0.2 & $(0.2-0.2)$ & $<0.001$ & 0.7 & $(0.7-0.8)$ & $<0.001$ \\
\hline ROC Curve & & $0.896(0.89-0.9)$ & & & & & & \\
\hline
\end{tabular}

\section{Discussion}

The prevalence of COPD in the 800,899 population was $3 \%$. This prevalence is lower than that published in the EPISCAN (10.2\%) and IBERPOC (9.1\%) studies [3]. It is also lower than the prevalence indicated in other studies conducted in the Spanish population $[16,18]$, which showed COPD prevalences around $9 \%$. The 3\% prevalence obtained in this study might respond to underreporting in the primary care setting caused by mild symptomatology (most patients would be classified as GOLD stages1-2, with $\mathrm{mMRC}<2$ and $\mathrm{CAT}<10$ ) and under-recording of spirometry results. Experts believe that a significant number of patients remain undiagnosed [6]. The higher proportion of men than women
( $77.1 \%$ vs $22.9 \%$, respectively) diagnosed with COPD is corroborated. However, the impact of shared risk factors such as age, smoking exposure and alcohol consumption appears to be greater in women.

As previously reported $[9,19]$, comorbidities are common in patients with COPD (prediabetes and diabetes, ischaemic cardiomyopathy, dyslipidaemia, hypertension, heart failure, atrial fibrillation, history of stroke, lung cancer and chronic kidney disease). Mild reductions in airway flux in patients with COPD have been associated with higher risk of stroke, ischaemic cardiomyopathy and sudden cardiac death. It has been suggested that COPD exacerbations generate inflammatory processes which increase C-reactive protein, fibrinogen and endothelin-1 
Table 4 Univariate and multivariate analysis of the study variables in women

\begin{tabular}{|c|c|c|c|c|c|c|c|c|}
\hline \multirow[t]{2}{*}{ Women } & \multicolumn{2}{|c|}{ Descriptive } & \multicolumn{3}{|c|}{ Crude effect } & \multicolumn{3}{|c|}{ Adjusted effect } \\
\hline & $\mathbf{N}$ & n (\%) & OR & $\mathrm{Cl}(95 \%)$ & $p$ & OR & $\mathrm{Cl}(95 \%)$ & $p$ \\
\hline Age grouped & 411,869 & & & & & & & \\
\hline $41-50$ & & $120,969(29.4 \%)$ & 1 & - & & 1 & - & \\
\hline $51-60$ & & 97,887 (23.8\%) & 2.8 & $(2.5-3.1)$ & $<0.001$ & 2.5 & $(2.2-2.8)$ & $<0.001$ \\
\hline $61-70$ & & 81,798 (19.9\%) & 4.2 & $(3.8-4.7)$ & $<0.001$ & 4.7 & $(4.1-5.3)$ & $<0.001$ \\
\hline $71-80$ & & $61,424(14.9 \%)$ & 7.1 & $(6.3-7.9)$ & $<0.001$ & 8.9 & $(7.8-10.1)$ & $<0.001$ \\
\hline 80 or more & & $49,791(12.1 \%)$ & 11.0 & $(9.8-12.2)$ & $<0.001$ & 14.5 & $(12.7-16.6)$ & $<0.001$ \\
\hline Smoking & 411,869 & 89,687 (21.8\%) & 2.4 & $(2.3-2.5)$ & $<0.001$ & 4.7 & $(4.4-5)$ & $<0.001$ \\
\hline Lung Cancer & 411,869 & $502(0.1 \%)$ & 5.9 & $(4.2-8.2)$ & $<0.001$ & 3.6 & $(2.5-5.2)$ & $<0.001$ \\
\hline Bronchiectasis & 411,869 & 4994 (1.2\%) & 32.6 & $(30.4-35)$ & $<0.001$ & 27.1 & $(25-29.3)$ & $<0.001$ \\
\hline Lung Cancer & 411,869 & $502(0.1 \%)$ & 5.9 & $(4.2-8.2)$ & $<0.001$ & 3.6 & $(2.5-5.2)$ & $<0.001$ \\
\hline Cor Pulmonale & 411,869 & $505(0.1 \%)$ & 13.2 & $(10.3-16.9)$ & $<0.001$ & 3.1 & $(2.3-4.1)$ & $<0.001$ \\
\hline Heart Failure & 411,869 & 8770 (2.1\%) & 8.2 & $(7.6-8.9)$ & $<0.001$ & 3.0 & $(2.7-3.3)$ & $<0.001$ \\
\hline OSAS & 411,869 & 2884 (0.7\%) & 4.4 & $(3.7-5.2)$ & $<0.001$ & 2.2 & $(1.8-2.6)$ & $<0.001$ \\
\hline Alcohol Consumption Risk Rate & 411,869 & & & & & & & \\
\hline No intake & & $172,572(41.9 \%)$ & 1 & & $<0.001$ & 1 & & $<0.001$ \\
\hline Low & & $33,322(8.1 \%)$ & 0.9 & $(0.8-1)$ & 0.002 & 0.9 & $(0.9-1)$ & 0.220 \\
\hline Moderate or High & & $1277(0.3 \%)$ & 1.9 & $(1.4-2.5)$ & $<0.001$ & 1.6 & $(1.2-2.3)$ & 0.005 \\
\hline NA & & $204,698(49.7 \%)$ & 0.4 & $(0.4-0.4)$ & $<0.001$ & 0.8 & $(0.7-0.8)$ & $<0.001$ \\
\hline Ischaemic Cardiomyopathy (no AMI) & 411,869 & $6400(1.6 \%)$ & 3.7 & $(3.3-4.1)$ & $<0.001$ & 1.3 & $(1.1-1.5)$ & $<0.001$ \\
\hline Osteopathy & 411,869 & $46,798(11.4 \%)$ & 2.2 & $(2.1-2.4)$ & $<0.001$ & 1.3 & $(1.2-1.4)$ & $<0.001$ \\
\hline Depression & 411,869 & $76,067(18.5 \%)$ & 1.6 & $(1.5-1.7)$ & $<0.001$ & 1.3 & $(1.2-1.3)$ & $<0.001$ \\
\hline Hypertension & 411,869 & $145,272(35.3 \%)$ & 3.0 & $(2.8-3.1)$ & $<0.001$ & 1.2 & $(1.1-1.3)$ & $<0.001$ \\
\hline $\mathrm{DM} 2$ & 411,869 & $47,166(11.5 \%)$ & 2.3 & $(2.1-2.4)$ & $<0.001$ & 1.1 & $(1-1.2)$ & 0.008 \\
\hline Anaemia & 411,869 & $46,826(11.4 \%)$ & 1.5 & $(1.4-1.6)$ & $<0.001$ & 1.1 & $(1-1.2)$ & 0.018 \\
\hline FA & 411,869 & 13,301 (3.2\%) & 4.0 & $(3.7-4.3)$ & $<0.001$ & 1.1 & $(1-1.3)$ & 0.014 \\
\hline Chronic kidney failure & 411,869 & $15,814(3.8 \%)$ & 3.0 & $(2.8-3.3)$ & $<0.001$ & 1.1 & $(1-1.2)$ & 0.108 \\
\hline Dyslipidaemia & 411,869 & $139,208(33.8 \%)$ & 1.8 & $(1.7-1.9)$ & $<0.001$ & 1.0 & $(0.9-1)$ & 0.336 \\
\hline Grouped BMI & 411,869 & & & & & & & \\
\hline Normal & & $37,589(9.1 \%)$ & 1 & - & & 1.0 & - & \\
\hline Overweight & & $59,722(14.5 \%)$ & 0.9 & $(0.8-1)$ & 0.003 & 0.8 & $(0.7-0.9)$ & $<0.001$ \\
\hline Obesity & & $59,011(14.3 \%)$ & 1.2 & $(1.1-1.3)$ & $<0.001$ & 1.0 & $(0.9-1.1)$ & 0.461 \\
\hline NA & & $255,547(62 \%)$ & 0.4 & $(0.4-0.5)$ & $<0.001$ & 0.9 & $(0.8-1)$ & 0.099 \\
\hline ROC Curve & & $0.863(0.86-0.87)$ & & & & & & \\
\hline
\end{tabular}

vasoconstrictor peptide in peripheral blood. These factors participate in the genesis of atherosclerosis [20], the decline in vascular function and endothelial dysfunction, causing cardiovascular complications. Another study conducted in a Spanish population found similar prevalences of hypertension (43\%), dyslipidaemia (33\%) and diabetes (16\%) [21]. Additionally, 13.3\% of COPD patients in our study suffered from anaemia, similarly to other series reporting percentages over $10 \%[22,23]$. Anaemia reduces exercise capacity. While the pathophysiology of anaemia in COPD is still debated, some authors have suggested that the inflammation of COPD mediated by INF-a, IL-1, IL-6 and IFN-gamma induces changes in iron metabolism, reducing the intestinal absorption of this metal and consequently affecting haematopoiesis [24]. Studies show an increase in the proportion of anaemia in older and more severe (GOLD) cases of COPD. For instance, Watz et al. reported a $14 \%$ prevalence of anaemia in patients with very severe COPD (GOLD 4) [25]. Since most COPD patients have a long history of smoking, lung cancer is more frequent in this group of patients. One study showed that cancer was the cause of death in $16.1 \%$ of patients with COPD, with lung cancer being the most common [26]. As previously described, bronchiectasis are a significant risk factor of COPD [27] 
COPD is more prevalent in older men. Prevalence is higher in men between 71 and 80 and over 80 years of age $(\mathrm{ORa}=18.8, p<0.001$ and $\mathrm{ORa}=29.1, p<0.001)$, respectively. Some research indicates that irreversible bronchial obstruction and decline of the FEV1 increase with age [28]. Another risk factor is moderate-high alcohol consumption, which is 1.3 higher in men with a diagnosis of COPD compared to those not diagnosed with this condition. Interestingly, in men with a diagnosis of COPD, moderate to high alcohol consumption is associated with higher use of tobacco [19]. In this respect, the association between smoking and COPD [7] has long been recognized, and men with a history of smoking have are 3.5 times more likely to have COPD. The most frequent comorbidities in men with COPD are cor pulmonale (5.3 times more prevalent in men with than without COPD) and heart failure (2.4 times more common in males with COPD). Our study has shown a lower ORa than the study by Villar et al., which reported an ORa of 4.5 of heart failure in patients with COPD [29]. Pathophysiologically, the use of systemic corticosteroids to treat exacerbations in moderate and severe COPD can generate fluid retention and over time, this increase in blood volume might cause heart failure [20]. Additionally, treatment with beta-adrenergic bronchodilators might cause tachycardia, an increase in myocardial oxygen consumption and thus aggravation of symptoms in patients with heart failure [30]. Anaemia was also 1.2 times more frequent in patients with COPD.

Older age is also a risk factor for COPD in women, and prevalence is 9 times higher in women between 71 and 80 years of age $(\mathrm{ORa}=8.8 ; p<0.001)$. Women with moderate to high alcohol consumption are at higher risk than men of COPD $(\mathrm{ORa}=1.6$ vs. ORa $=1.3$, respectively). Similarly, the risk in women with a history of smoking is also higher than in men (risk 4.7 vs. 3.5 times higher to present COPD, respectively). Some authors have suggested that the higher risk of women to develop COPD can be explained by their higher susceptibility to the effects of smoking, their longer exposure to indoor pollution, and by anatomic and hormonal characteristics $[12,31]$. The risk of presenting bronchiectasis was higher in women with $\mathrm{COPD}(\mathrm{ORa}=27.1)$ than in their male counterparts $(\mathrm{ORa}=20.5)$. This finding has also been described by Oliveira et al. [27], which analysed a cohort of 20,047 patients with bronchiectasis from 36 health centres in Spain, and concluded that $54.9 \%$ were women. The most common causes for bronchiectasis were systemic, idiopathic and post-infectious diseases. Other comorbidities such as obstructive sleep apnoea syndrome (OSAS), are also more common in women than in men (twofold increase in prevalence in women with COPD, compared to 1.7 in men with COPD). The ORc for diabetes was 2.3 for male and female COPD patients. This risk is attributed to the hyperglycaemia caused by the treatment of moderate and severe COPD exacerbations with systemic corticosteroids, which over time might cause diabetes in a subgroup of COPD patients [32]. However, this risk decreased in the multivariate analysis.

\section{Limitations}

Since the information has been obtained from the SIDIAP database (data that originate from the electronic medical records), under-recording should be considered. An additional limitation to consider is the fact that no spirometric curves of patients included in the study have been analysed. Also, in a prevalence study the associations might not be causal. For instance, comorbidities such as bronchiectasis can be risk factors for COPD, whereas associated diseases such as cor pulmonale could be the result of this condition. Furthermore, the large population sample might produce statistically significant differences with no clinical relevance. The classification of the database follows the algorithm proposed by Barrecheguren et al. [15], and thus false positives and false negatives need to be considered. Another limitation when working with a large database would be under-reporting some data from the medical records of patients, as the FEV1/FVC case. In order to minize this fact, Barrecheguren et al. [15] algorithm was used in order to be able to include higher number of patients and to ensure high statistical power of the study.

\section{Conclusion}

COPD prevalence in the SIDIAP cohort is lower than expected (3\%), probably due to under-recording of clinical information in primary care medical records. Patients suffering from COPD present high comorbidity rates. Although in general risk factors are the same in both genders, women appear to be more susceptible to harmful exposures such as smoking and present a higher proportion of bronchiectasis and OSAS. Understanding associated comorbidities is crucial for an integral approach to COPD. Further research in similar cohorts would be required to provide new evidence on the prevalence of COPD as well to determine the incidence of disease exacerbation based on clinical-epidemiological features.

\section{Availability and data and materials}

The datasets used and/or analysed during the current study are available from the corresponding author on reasonable request.

Acknowledgements

Not applicable. 


\section{Authors' contributions}

JMC, MO, JRM and PG designed the study. JMC and PG wrote the manuscript with support from JRM, MO and MA. JRM, MA, FB and PG verified the analytical methods. JMC, MO, JRM, MTC, MA, FB and PG contributed to the interpretation the results. PG and FB supervised the findings of this work. JRM designed the figure. PG supervised the project. All authors provided critical feedback and helped shape the research and contributed to the final version of the manuscript. All authors read and approved the final manuscript.

\section{Funding}

This research received no specific grant any funding agency in the public, commercial, or not-for-profit sectors.

\section{Ethics approval and consent to participate}

The study was approved by the Clinical Research Ethics Committee of the IDIAP Jordi Gol of Barcelona (P13/063). This study is the result of the research project presented by our research Group to the "Information System for the Development in Research in Primary Care" (SIDIAP) 2016 grant convened by the Jordi Gol Institute for Primary Care Research (IDIAP) of Barcelona, which was the winner. The IDIAP, a public institution of the Catalan Health Service (ICS), provided us with clinical data from the computerized medical records of all patients in Catalonia (Spain). We did not directly access the clinical records of the patients, but the project detailed the clinical variables that were required and IDIAP provided them us. IDIAP never provided us the identification data (name, surname, address, telephone number, identification number...) of any patient. For more information about SIDIAP grant: https:// www.idiapjgol.org/index.php/en/services/guidelines-on-good-research-pract ice-2 https://www.sidiap.org

\section{Consent for publication}

Not Applicable.

\section{Competing interests}

The authors declare that they have not competing interests.

\section{Author details}

${ }^{1}$ Unitat Docent Multiprofessional d'Atenció Familiar i Comunitària (UDMAFiC) Lleida-ICS, Gerència Territorial de Lleida ICS, Lleida, Catalonia, Spain. ${ }^{2}$ Atenció Primària, Institut Català de la Salut (ICS), Lleida, Catalonia, Spain. ${ }^{3}$ Faculty of Medicine, Universitat de Lleida (UdL), Lleida, Catalonia, Spain. ${ }^{4}$ Biomedical Research Institute of Lleida (IRBLleida), Lleida, Catalonia, Spain. ${ }^{5}$ Cardiovascular Epidemiology Unit, Hospital Universitari Vall d'Hebron, Barcelona, Catalonia, Spain. ${ }^{6}$ Research Support Unit, Direcció d'Atenció Primària ICS-Lleida; Institut Universitari d'Investigació en Atenció Primària (IDIAP Jordi Gol), Institut Català de la Salut, Lleida, Catalonia, Spain. ${ }^{7}$ Agència de Salut Pública de Catalunya, Departament de Salut, Lleida, Catalonia, Spain. ${ }^{8}$ Hospital Universitari Arnau de Vilanova, Lleida, Catalonia, Spain. ${ }^{9}$ Centro de Investigación Biomédica en Red de Enfermedades Respiratorias (CIBERES), Madrid, Spain. ${ }^{10}$ Centro de Investigación Biomédica en Red de Epidemiología y Salud Pública (CIBERESP), Madrid, Spain.

Received: 21 March 2020 Accepted: 1 January 2021

Published online: 28 January 2021

\section{References}

1. Anar C, Bicmen C, Yapicioglu S, et al. Evaluation of clinical data and antibody response following influenza vaccination in patients with chronic obstructive pulmonary disease. New Microbiol. 2010;33(2):117-27.

2. Miravitlles M, Soriano JB, García-Río F, et al. Prevalence of COPD in Spain: impact of undiagnosed COPD on quality of life and daily life activities. Thorax. 2009;64(10):863-8.

3. Soriano JB, Ancochea J, Miravitlles M, et al. Recent trends in COPD prevalence in Spain: a repeated cross-sectional survey 1997-2007. Eur Respir J. 2010;36(4):758-65.

4. Atsou K, Chouaid C, Hejblum G. Variability of the chronic obstructive pulmonary disease key epidemiological data in Europe: systematic review. BMC Med. 2011;9(7).
5. Jaén A, Ferrer A, Ormaza I, et al. Prevalence of chronic bronchitis, asthma and airflow limitation in an urban-industrial area of Catalonia. Arch Bronconeumol. 1999;35(3):122-8.

6. Montserrat-Capdevila J, Seminario MA, Godoy P, et al. Prevalence of chronic obstructive pulmonary disease (COPD) not diagnosed in a population with cardiovascular risk factors. Med Clin. 2018;18:1-7.

7. Shahab L, Jarvis MJ, Britton J, et al. Prevalence, diagnosis and relation to tobacco dependence of chronic obstructive pulmonary disease in a nationally representative population sample. Thorax. 2006;61(12):1043-7.

8. Feary JR, Rodrigues LC, Smith CJ, et al. Prevalence of major comorbidities in subjects with COPD and incidence of myocardial infarction and stroke: a comprehensive analysis using data from primary care. Thorax. 2010;65(11):956-62.

9. Lahousse L, Niemeijer MN, van den Berg ME, et al. Chronic obstructive pulmonary disease and sudden cardiac death: the Rotterdam study. Eur Heart J. 2015;36(27):1754-61.

10. Mannino DM, Buist AS. Global burden of COPD: risk factors, prevalence, and future trends. Lancet. 2007;370(9589):765-73.

11. Aryal S, Diaz-Guzman E, Mannino DM. Influence of sex on chronic obstructive pulmonary disease risk and treatment outcomes. Int J Chron Obstruct Pulmon Dis. 2014;9:1145-54.

12. Ntritsos G, Franek J, Belbasis L, et al. Gender-specific estimates of COPD prevalence: a systematic review and meta-analysis. Int J Chron Obstruct Pulmon Dis. 2018;13:1507-14.

13. Soler-Cataluña JJ, Martínez-García MÁ, Serra PC. Multidimensional impact of COPD exacerbations]. Arch Bronconeumol. 2010;46(Suppl 1):12-9.

14. Bolíbar B, Fina Avilés F, et al. SIDIAP database: electronic clinical records in primary care as a source of information for epidemiologic research. Med Clin (Barc). 2012;138(14):617-21.

15. Barrecheguren $M$, Monteagudo $M$, Ferrer J, et al. Treatment patterns in COPD patients newly diagnosed in primary care: a population-based study. Respir Med. 2016;111:47-53.

16. Jaén Díaz Jl, de Castro Mesa C, Gontán García-Salamanca MJ, et al. Prevalence of chronic obstructive pulmonary disease and risk factors in smokers and ex-smokers. Arch Bronconeumol. 2003;39(12):554-8.

17. Mirza S, Clay RD, Koslow MA, et al. COPD guidelines: a review of the 2018 GOLD report. Mayo Clin Proc. 2018;93(10):1488-502.

18. Brotons B, Pérez JA, Sánchez-Toril F, et al. The prevalence of chronic obstructive pulmonary disease and asthma: a cross-sectional study. Arch Bronconeumol. 1994:30(3):149-52.

19. Ramsey SD, Hobbs FDR. Chronic obstructive pulmonary disease, risk factors, and outcome trials: comparisons with cardiovascular disease. Proc Am Thorac Soc. 2006;3(7):635-40.

20. Souverein PC, Berard A, Van Staa TP, et al. Use of oral glucocorticoids and risk of cardiovascular and cerebrovascular disease in a population based case-control study. Heart. 2004;90(8):859-65.

21. Comeche Casanova L, Echave-Sustaeta JM, García Luján R, et al. Prevalence of anaemia associated with chronic obstructive pulmonary disease. Study of associated variables. Arch Bronconeumol. 2013;49(9):383-7.

22. John M, Hoernig S, Doehner W, et al. Anemia and inflammation in COPD. Chest. 2005;127(3):825-9.

23. Cote C, Zilberberg MD, Mody SH, et al. Haemoglobin level and its clinical impact in a cohort of patients with COPD. Eur Respir J. 2007;29(5):923-9.

24. Weiss G, Goodnough LT. Anemia of chronic disease. N Engl J Med. 2005:352(10):1011-23.

25. Watz H, Waschki B, Boehme C, et al. Extrapulmonary effects of chronic obstructive pulmonary disease on physical activity: a cross-sectional study. Am J Respir Crit Care Med. 2008;177(7):743-51.

26. Divo M, Cote $C$, de Torres JP, et al. Comorbidities and risk of mortality in patients with chronic obstructive pulmonary disease. Am J Respir Crit Care Med. 2012;186(2):155-61.

27. Olveira C, Padilla A, Martínez-García M-Á, et al. Etiology of bronchiectasis in a cohort of 2047 patients. an analysis of the spanish historical bronchiectasis registry. Arch Bronconeumol. 2017;53(7):366-74.

28. Halbert RJ, Isonaka S, George D, et al. Interpreting COPD prevalence estimates: what is the true burden of disease? Chest. 2003:123(5):1684-92.

29. Villar F, Mendez M. EPOC e insuficiencia cardiaca. Arch Bronconeumol. 2009;45(8):383-93.

30. Au DH, Udris EM, Fan VS, Curtis JR, et al. Risk of mortality and heart failure exacerbations associated with inhaled beta-adrenoceptor agonists 
among patients with known left ventricular systolic dysfunction. Chest. 2003;123(6):1964-9.

31. Ezzati M, Kammen D. Indoor air pollution from biomass combustion and acute respiratory infections in Kenya: an exposure-response study. Lancet (London, England). 2001;358(9282):619-24

32. Chillón Martín MJ, Díez J de M, Moreno AF, et al. COPD and endocrine and metabolic alterations. Arch Bronconeumol. 2009;45 Suppl 4:42-6.

\section{Publisher's Note}

Springer Nature remains neutral with regard to jurisdictional claims in published maps and institutional affiliations.
Ready to submit your research? Choose BMC and benefit from:

- fast, convenient online submission

- thorough peer review by experienced researchers in your field

- rapid publication on acceptance

- support for research data, including large and complex data types

- gold Open Access which fosters wider collaboration and increased citations

- maximum visibility for your research: over $100 \mathrm{M}$ website views per year

At BMC, research is always in progress.

Learn more biomedcentral.com/submissions 